\title{
THE MODE OF ACTION OF A MERCURIAL DIURETIC IN MAN
}

\author{
BY R. A. DALE ${ }^{1}$ AND P. H. SANDERSON
}

(From the Department of Medicine, St. Mary's Hospital Medical School, London)

(Submitted for publication September 9, 1952; accepted March 23, 1954)

Govaerts (1) and Bartram (2) established that the diuretic action of organic mercury compounds is renal rather than extrarenal. The use of clearance techniques has further shown that the glomerular filtration rate does not increase in man during a mercurial diuresis $(3,4)$. The increased rate of water excretion must, therefore, be due to diminished tubular reabsorption.

Attempts to carry the analysis still further have led to divergent views. Duggan and Pitts (5) conclude that the site of action is in the distal segment of the tubule, whereas Mudge, Foulks, and Gilman (6) and Weston, Grossman, and Leiter (7) believe it is in the proximal segment. In this paper we present data which we consider to support the former view.

\section{METHODS}

The subjects were normal male medical students or doctors. Except where it is stated to the contrary, the subjects came to the laboratory in the morning, having taken nothing by mouth since the previous evening. The experiments were begun as near 9:30 a.m. as possible. Urine was collected at 30 -minute intervals by voluntary micturition, without a catheter; the collection periods were usually reduced to 15 minutes at the peak of the diuresis.

The mercurial diuretic used was Mersalyl, obtained as a solid from British Drug Houses Ltd.; unless otherwise stated, the dose was $0.2 \mathrm{Gm}$., which was dissolved in 20 ml. sterile distilled water and injected intravenously as soon as possible after solution. The injection was given slowly over a period of 10 minutes to avoid possible toxic effects on the heart resulting from a momentarily excessive blood level of the drug. No theophylline was given with these injections.

During the experiments the subjects sat in a chair or reclined on a couch; their activity was restricted to that necessary for passing urine. They took nothing by mouth, except as stated in the text. Smoking was prohibited. The chemical methods used were as follows: Sodium: direct reading flame photometer; Chloride: electrometric titration (8); Inulin: Harrison (9).

\footnotetext{
1 Ernest Hart Memorial Scholar.
}

\section{RESULTS}

The effect of Mersalyl in subjects on a normal diet

Figure 1 illustrates a typical experiment. After three preliminary thirty-minute periods, $0.2 \mathrm{Gm}$. Mersalyl was injected intravenously, and it can be seen that the urine sodium and chloride concentrations, initially at a level of some $300 \mathrm{mEq}$. per liter, fell sharply to about $150 \mathrm{mEq}$. per liter at the height of the diuresis. Table I shows the results of 12 such experiments. In nine of these, the effect of Mersalyl was to cause a fall in the urinary concentration of both sodium and chloride at the peak of diuresis, producing a pattern of excretion similar to that shown in Figure 1 . In the remaining three experiments (R. E. W., J. E. G., and E. R. D.) Mersalyl produced the opposite effect. The diureses in the experiments on R. E. W. and J. E. G. were irregular and unsatisfactory, reaching peak rates of only 3.7 and 5.0 $\mathrm{ml}$. per min., respectively, and it seems possible that some interfering factor was masking the usual response. E. R. D. had a satisfactory diuresis, but his initial urine sodium concentration was well below his plasma sodium level.

In the four experiments marked with an asterisk in Table $I$, the subjects drank 0.9 per cent sodium chloride solution throughout the experiment at a rate of $200 \mathrm{ml}$. per hr. The object of this was to increase the subject's reserves of sodium and chloride, in the hope that a more profuse diuresis would result when Mersalyl was given. Control experiments without Mersalyl had previously shown that drinking saline in this way caused no significant increase in urine flow even if continued for seven hours. No increase in diuresis following Mersalyl occurred, and in fact in two experiments the diuresis was unsatisfactory; in the other two, however, good diuresis with the typical concentration changes were observed. It seemed simplest, therefore, to group all four experiments 


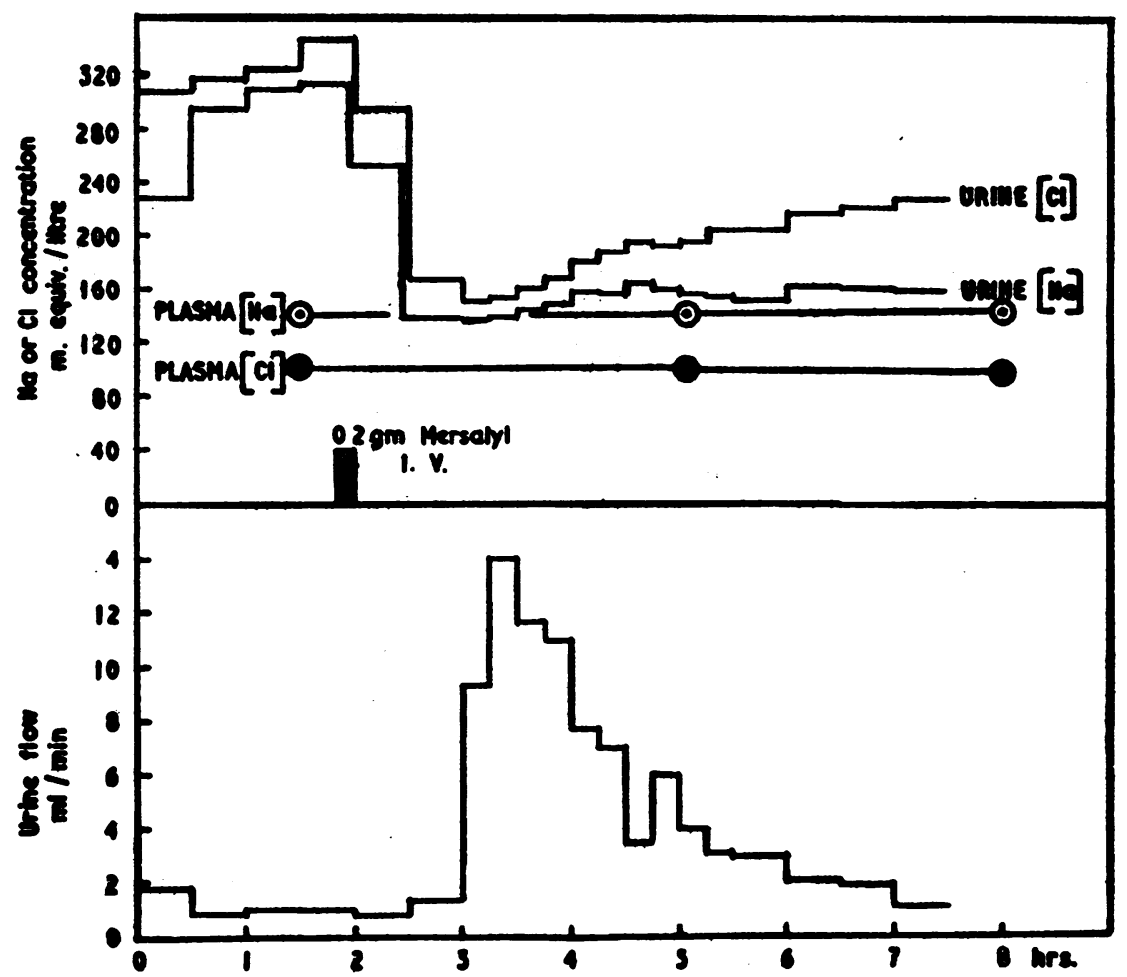

Fig. 1. The Effect of Mersalyl on the Urinary Concentration of Sodium and Chloride in a Subject Taking a Normal Diet

The plasma levels of sodium and chloride are indicated by open dotted circles and closed circles, respectively.

with the rest in Table $I$, since the results seemed to show no obvious distinguishing features.

\section{The effect of Mersalyl in subjects on a diet poor in salt}

The marked depression of urine sodium and chloride concentrations shown in the experiments of Table I prompted us to enquire whether a similar effect would be seen if the initial urine concentrations were low rather than high. Accordingly, some normal subjects were given a diet supplying some $0.5 \mathrm{Gm}$. of sodium and $1 \mathrm{Gm}$. of chloride daily for two to three days, and then the effect of Mersalyl was observed as before. Figure 2 illustrates a typical result of this procedure. It will be seen that the injection of Mersalyl was followed by a rise rather than a fall in the urinary concentrations of sodium and chloride.

The results of seven such experiments are set out in Table II. In every case the injection of Mersalyl caused a substantial rise in the concentrations of sodium and chloride in the urine.
Satisfactory diuresis was obtained in every case except one (E. R. D.), and even in this instance well marked concentration changes were seen.

It is clear, therefore, from Figures 1 and 2 and from the data contained in Tables I and II, that the effect of Mersalyl is to raise the urinary concentrations of sodium and chloride if they are low initially, and to lower them if they are high. In Figures 1 and 2 the plasma sodium and chloride levels are also indicated, by open dotted circles and closed circles, respectively. In the case of sodium the urinary concentrations at the peak of diuresis approached closely to the plasma levels in both experiments, whereas with chloride the concentrations tended, not towards the plasma level, but towards a figure some 50 per cent higher. Similar changes are found in all but three of the 19 experiments recorded in Tables I and II. This aspect of the results has been summarized in Figure 3 , which indicates the changes in

$$
\frac{\text { urine concentration }}{\text { plasma concentration }}
$$


TABLE I

The effect of Mersalyl on urinary sodium and chloride concentrations in subjects taking a normal diet *

\begin{tabular}{|c|c|c|c|c|c|c|c|}
\hline \multirow[b]{2}{*}{ Subject } & \multicolumn{2}{|c|}{$\begin{array}{l}\text { Urine sodium } \\
\text { concentration } \\
\left(m E_{q} / L .\right)\end{array}$} & \multirow{2}{*}{$\begin{array}{c}\text { Plasma } \\
\text { sodium } \\
\left(m E E_{q} / L .\right)\end{array}$} & \multicolumn{2}{|c|}{$\begin{array}{l}\text { Urine chloride } \\
\text { concentration } \\
\left(m E_{q} / L .\right)\end{array}$} & \multirow{2}{*}{$\begin{array}{c}\text { Plasma } \\
\text { chloride } \\
\text { (mER./L.) }\end{array}$} & \multirow{2}{*}{$\begin{array}{l}\text { Urine flow } \\
\text { at peak } \\
\text { (ml./min.) }\end{array}$} \\
\hline & Initial & Peak & & Initial & Peak & & \\
\hline $\begin{array}{l}\text { R. A. D. } \\
\text { R. E. W. } \\
\text { I. C.S. N. } \\
\text { R. B. P. } \\
\text { M.B. T. } \\
\text { P.S. } \\
\text { P. A. B. } \\
\text { E. R. D. } \\
\text { B. C. } \\
\text { J.S. B. } \dagger \\
\text { T. C. W. } \dagger \\
\text { J.E. G. } \dagger\end{array}$ & $\begin{array}{l}282.5 \\
180 \\
229 \\
277 \\
190 \\
193 \\
166 \\
114 \\
172.5 \\
114 \\
187 \\
159\end{array}$ & $\begin{array}{l}195 \\
205 \\
163 \\
138 \\
134 \\
160 \\
144 \\
147 \\
159 \\
90 \\
177.5 \\
171\end{array}$ & $\begin{array}{l}152 \\
143.5 \\
143.5 \\
140 \\
146 \\
146 \\
143 \\
144 \\
144 \\
141 \\
142.5 \\
142.5\end{array}$ & $\begin{array}{l}332 \\
189 \\
243 \\
315 \\
177 \\
219 \\
247 \\
152 \\
218 \\
142 \\
234 \\
245\end{array}$ & $\begin{array}{r}193 \\
212 \\
160 \\
153 \\
134 \\
168 \\
150 \\
160 \\
157 \\
96 \\
184 \\
196\end{array}$ & $\begin{array}{l}102 \\
98 \\
100.5 \\
100 \\
103.5 \\
101.5 \\
98 \\
101 \\
100.5 \\
104 \\
101 \\
101\end{array}$ & $\begin{array}{r}8.7 \\
3.7 \\
9.9 \\
14.0 \\
6.8 \\
6.9 \\
12.1 \\
9.5 \\
12.9 \\
4.9 \\
8.6 \\
5.0\end{array}$ \\
\hline
\end{tabular}

* The figures in the columns headed 'initial' are the means of the concentration of sodium or chloride in the periods (not less than 3 in number) before the injection of Mersalyl.

The figures in the columns headed 'peak' are the concentrations of sodium or chloride in the specimen showing the maximum rate of water excretion in each experiment.

† Subject drank 0.9 per cent sodium chloride solution, $200 \mathrm{ml}$. per hr., throughout the experiment.

( $U / P$ ratio) for sodium and chloride. The mean of all the sodium ratios at the peak of diuresis was 0.98 , with a standard deviation of 0.25 ; the corresponding figure for chloride was 1.50 , with a standard deviation of 0.35 .

The effect of Mersalyl on a maximum water diuresis

These results shed some light on the action of Mersalyl on the kidney as a whole, but, as pointed out in the discussion, they do not allow a final decision to be taken between a proximal or distal tubular site of action. It seemed that further evidence on this point might be obtained in the following way.

Current theory (based, admittedly, on indirect evidence) supposes that the fraction of water reabsorption which is under the control of the antidiuretic hormone of the posterior pituitary is carried out in the distal tubule. This water reabsorp-

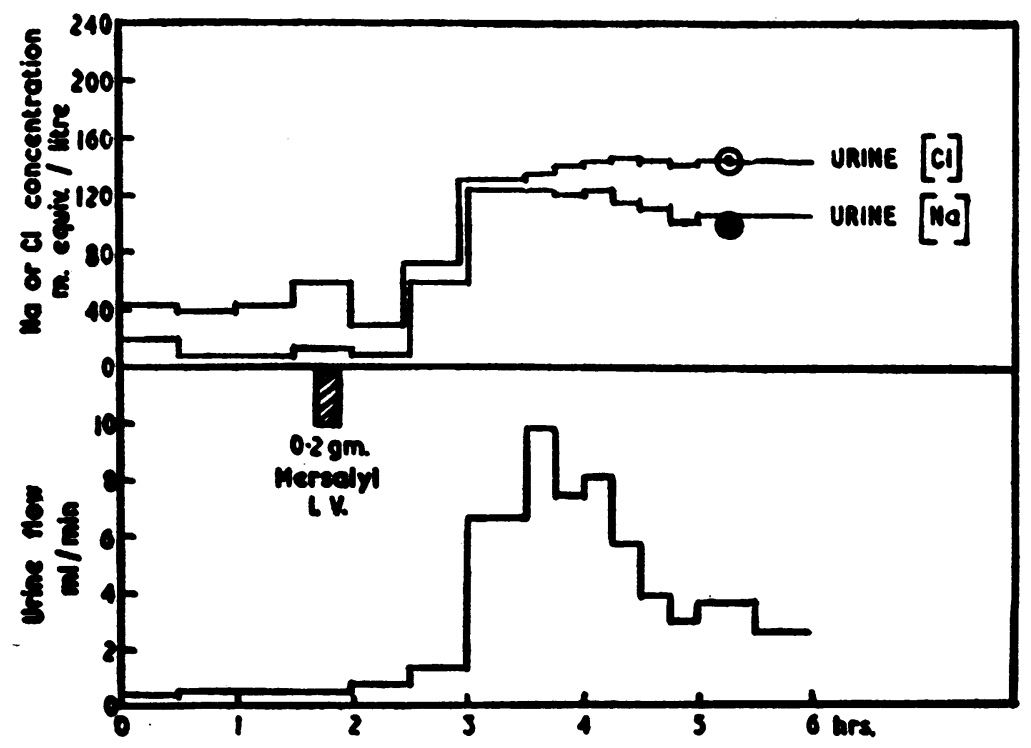

Fig. 2. The Effect of Mersalyl on Urinary Sodiuy and Chloride in a Subject Taking a Diet Poor in Salt

Plasma sodium and chloride indicated as in Figure 1. 
THE MODE OF ACTION OF A MERCURIAL DIURETIC IN MAN

TABLE II

Effect of Mersalyl on urinary sodium and chloride concentration in subjects taking a diet poor in salt*

\begin{tabular}{|c|c|c|c|c|c|c|c|}
\hline \multirow[b]{2}{*}{ Subject } & \multicolumn{2}{|c|}{$\begin{array}{l}\text { Urine sodium } \\
\text { concentration } \\
\text { (mEq./L.) }\end{array}$} & \multirow{2}{*}{$\begin{array}{c}\text { Plasma } \\
\text { sodium } \\
(m E q . / L .)\end{array}$} & \multicolumn{2}{|c|}{$\begin{array}{l}\text { Urine chloride } \\
\text { concentration } \\
\left(m E_{q} / L .\right)\end{array}$} & \multirow{2}{*}{$\begin{array}{c}\text { Plasma } \\
\text { chioride } \\
\left(m E_{q .} / L .\right)\end{array}$} & \multirow{2}{*}{$\begin{array}{l}\text { Urine flow } \\
\text { at peak } \\
\text { (wal./min.) }\end{array}$} \\
\hline & Initial & Peak & & Initial & Peak & & \\
\hline $\begin{array}{l}\text { T. C. W. } \\
\text { E. R. D. } \\
\text { I. C. S. N. } \\
\text { P. A. B. } \\
\text { B. C. } \\
\text { M. H. } \\
\text { W. R. C. }\end{array}$ & $\begin{array}{r}31 \\
8 \\
37 \\
12 \\
25 \\
15 \\
11\end{array}$ & $\begin{array}{r}110 \\
134 \\
135 \\
125 \\
122 \\
126 \\
46\end{array}$ & $\begin{array}{l}143 \\
140 \\
139 \\
144 \\
144 \\
143 \\
142\end{array}$ & $\begin{array}{l}73 \\
41 \\
79 \\
42 \\
61 \\
31 \\
12\end{array}$ & \begin{tabular}{r|}
122 \\
156 \\
149 \\
136 \\
140 \\
132 \\
56
\end{tabular} & $\begin{array}{c}99.7 \\
100.5 \\
97 \\
101 \\
97 \\
94 \\
96.5\end{array}$ & $\begin{array}{r}7.9 \\
3.5 \\
8.3 \\
9.9 \\
5.8 \\
6.2 \\
16.8\end{array}$ \\
\hline
\end{tabular}

* The subjects took a diet supplying about $0.5 \mathrm{Gm}$. sodium and $1 \mathrm{Gm}$. chloride per day for three days prior to the experiments, except in the cases of E.R. D. and I. C. S. N., where the period was two days.

tion can be suppressed by inducing a maximum water diuresis. If Mersalyl inhibits water reabsorption in the distal tubule, then it should be incapable of producing any augmentation of a maximum water diuresis. If, on the other hand, it inhibits proximal water reabsorption, it should cause a conspicuous increase in urine flow even at the height of water diuresis.

Urine flows of the order of 15 to $18 \mathrm{ml}$. per min-
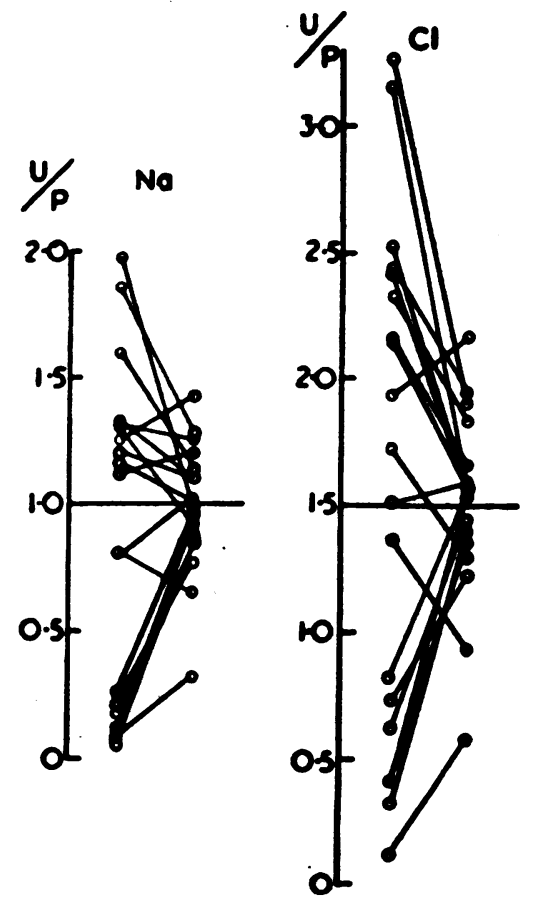

Fic. 3. Changes in U/P Ratio for Sodium and ChloRIDE IN THE EXPERIMENTS OF TABLES I AND II

Each oblique line represents a single experiment: the point at its left-hand end indicates the $U / P$ ratio before Mersalyl was given, and that at the right-hand end the ratio at the peak of diuresis. ute can be produced without difficulty in most subjects provided enough water is drunk sufficiently rapidly; but these rates are seldom exceeded, and cannot be maintained for more than about an hour, no matter how great the intake. Moreover, the maximum rate attainable depends on the time of day, being greatest in the morning and progressively less as the day goes on (10). It was, therefore, impossible to produce a constant background of maximum water diuresis, against which the effect of an injection of Mersalyl could be presented. Instead, it was necessary to carry out two experiments in each subject: a control experiment, in which the course of the ordinary maximum water diuresis, without Mersalyl, was demonstrated, and a Mersalyl experiment, in which, at the same hour of another day, the same amount of water was drunk and an injection of Mersalyl was given.

The plan of the actual experiments is best seen from Figure 4, which shows the results obtained in subject C. M. F. At the top of the figure is indicated the water intake, and it can be seen that a peak rate of excretion of $18 \mathrm{ml}$. per min. was reached in the control experiment. In order to make the peak of the mercurial action coincide with the peak of the water diuresis, the Mersalyl was given half an hour before the first water was drunk, and in this experiment a peak rate of $18.5 \mathrm{ml}$. per min. was reached.

Table III shows the results of six such experiments. It will be seen that in every case Mersalyl produced a slight augmentation of the peak rate of urine flow; but this increase was relatively small when considered in conjunction with the rates of urine flow, and was less than $3 \mathrm{ml}$. per min. in 


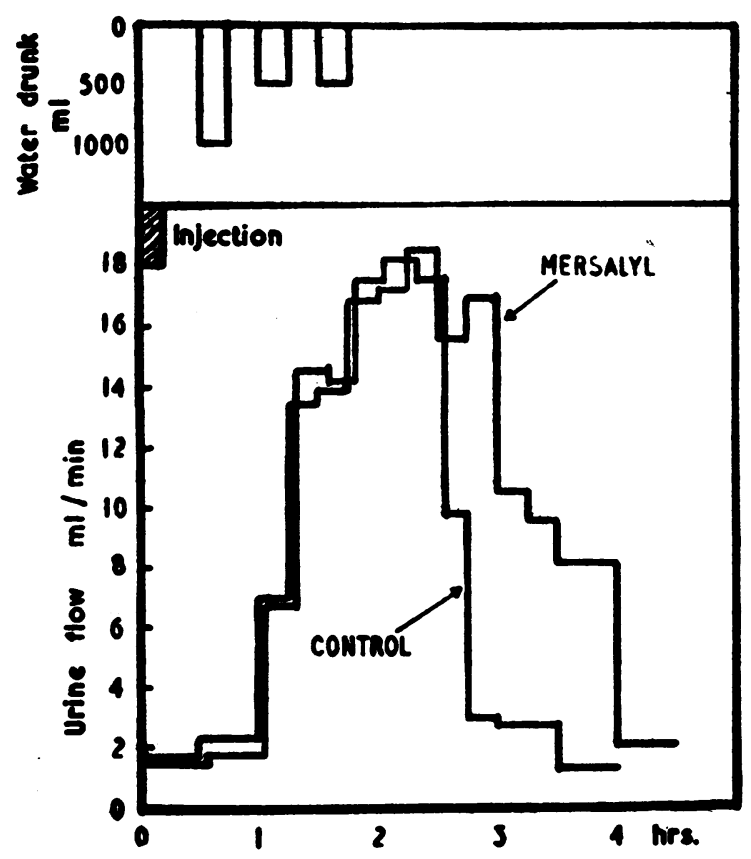

Fig. 4. Diuresis Obtained (a) by Administering Water Alone (Sex Upper Panel) and (b) Administering the Same Amount of Water and Injecting 0.2 Gy. MersalyL

The maximum rates of urine flow in the two experiments are nearly the same.

every case except one (P. A. O.). Similar results have recently been recorded by Capps, Wiggins, Axelrod, and Pitts (11). In their experiments, and in experiments by other authors using Mersalyl, depression of the glomerular filtration rate following injection of the drug was occasionally seen. Had this occurred regularly in our subjects, it might have sufficed to mask a proximal action of Mersalyl. We, therefore, repeated the experiments with simultaneous inulin clearance determinations. Figure 5 shows a typical result,

TABLE III

Effect of Mersalyl on peak rate of water excretion during maximum water diuresis

\begin{tabular}{lcc}
\hline & \multicolumn{2}{c}{$\begin{array}{c}\text { Maximum rate of urine flow } \\
\text { (ml./min.) }\end{array}$} \\
\cline { 2 - 3 } Subject & Control & Mersalyl \\
\hline G. M. F. & 18.1 & 18.5 \\
J. A. K. & 17.0 & $19.7^{*}$ \\
B. & 9.3 & 10.1 \\
E. & 14.5 & 16.2 \\
P. A. O. & 15.1 & 19.2 \\
A. W. & 13.5 & 15.5 \\
\hline
\end{tabular}

- Needle slipped out of vein before completion of injection. Estimated dose of Mersalyl $=0.145 \mathrm{Gm}$.

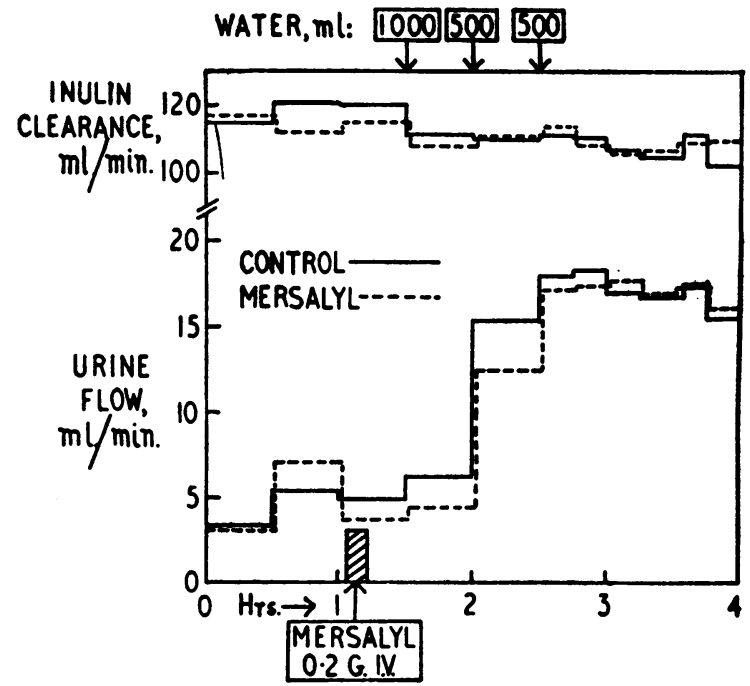

Fig. 5. Urine Flow and Inulin Clearance in a Pair of Experiments of the Same Plan as Those in FIGURE 4

The injection of Mersalyl has no discernible effect either on the water diuresis or on the inulin clearance.

and Table IV summarizes the data from five such experiments. A conspicuous fall in filtration rate following Mersalyl administration occurred in the case of J. B., whose diuretic response was unusual in that the peak flow with water alone was greater than that with water and Mersalyl. In the remaining experiments changes in filtration were insignificant ; the result in the case of W. is almost certainly an artefact due to incomplete bladder emptying. We conclude that a fall in filtration rate may sometimes follow the injection of Mersalyl, but that

TABLE IV

Changes in inulin clearance during maximum water diuresis with and without Mersalyl *

\begin{tabular}{|c|c|c|c|c|}
\hline \multirow[b]{2}{*}{ Subject } & \multicolumn{2}{|c|}{ Control } & \multicolumn{2}{|c|}{ Mersalyl } \\
\hline & $\begin{array}{c}\text { Max. } \\
\text { urine } \\
\text { flow } \\
(\text { ml. } / \text { min. })\end{array}$ & $\underset{(m l . / m i n .)}{\operatorname{CrN}_{\text {IIs }}}$ & 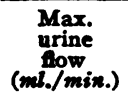 & $\underset{(m l . / m i n .)}{\operatorname{CIn}_{\text {min }}}$ \\
\hline $\begin{array}{l}\text { P. H. S. } \\
\text { A. L. } \\
\text { J. Bl. } \\
\text { J. Ba. } \\
\text { A. R. W. }\end{array}$ & $\begin{array}{l}18.3 \\
15.0 \\
18.0 \\
14.9 \\
16.3 \dagger\end{array}$ & $\begin{array}{l}110 \\
121 \\
149 \\
134 \\
132 \dagger\end{array}$ & $\begin{array}{l}17.7 \\
19.1 \\
13.7 \\
14.9 \\
13.9\end{array}$ & $\begin{array}{l}106 \\
125 \\
117 \\
124 \\
113\end{array}$ \\
\hline
\end{tabular}

* The figures quoted for each experiment are the maximum rate of urine flow reached, and the simultaneous inulin clearance during that period.

$\dagger$ Results of this period probably too high as a result of faulty bladder emptying. Figures for preceding and following periods were: urine flow, 12.0 and $14.6 \mathrm{ml}$. per min.; inulin clearance, 106 and $106 \mathrm{ml}$. per min. 
this is usually so slight as not to affect the argument outlined above; on the one occasion (J. B.) when a considerable fall occurred, it was accompanied by a conspicuously reduced peak urine flow.

\section{Effect of simultaneous administration of Mersalyl and pituitary antidiuretic hormone}

Capps, Wiggins, Axelrod, and Pitts (11) studied the simultaneous effect of mercurial diuretics and pituitary antidiuretic hormone, and concluded that the latter was able to reverse the fall in urinary osmotic pressure caused by mercurials. They gave Pitressin injections after mercurials, at a time when our experience suggests that urinary sodium and chloride concentrations are likely in the natural course of events to be rising again. We have investigated this point by the opposite technique, injecting Mersalyl into subjects while they were receiving a steady infusion of Pitressin (80-120 $\mathrm{mU}$ per hr., with priming dose of 200 $\mathrm{mU})$.

Some of these subjects were on normal and others on salt-poor diets. The results are summarized in Table V. The existence of an antagonistic effect of the Pitressin is shown by the fact that, out of four experiments with normal diet and three experiments with salt-poor diet, no diuresis was obtained in one and two experiments, respectively. In those experiments in which a diuresis was obtained, the changes in $\mathrm{U} / \mathrm{P}$ ratios were comparable with those obtained in similar experiments without Pitressin (compare Figure 3 ). In those experiments in which there was no diuresis, the changes were towards ratios considerably higher than 1 for sodium and 1.5 for chloride, so that the average $U / P$ for the whole series was

TABLE V

Effect of Mersalyl on urine flow and $U / P$ ratio for sodium and chloride in subjects receiving a continuous intravenous infusion of Pitressin

\begin{tabular}{|c|c|c|c|c|c|c|}
\hline \multirow[b]{2}{*}{ Subject } & \multicolumn{2}{|c|}{ Urine flow } & \multicolumn{2}{|c|}{ U/P sodium } & \multicolumn{2}{|c|}{ U/P chloride } \\
\hline & Initial & Peak & Initial & Peak & Initial & Peak \\
\hline $\begin{array}{l}\text { H. J. W. } \\
\text { A. B. } \\
\text { A. L. } \\
\text { J. B. } \\
\text { D. G. L.* } \\
\text { N. B. P.* } \\
\text { G. H. G.* }\end{array}$ & $\begin{array}{l}1.03 \\
1.21 \\
1.57 \\
1.1 \\
0.76 \\
0.70 \\
0.85\end{array}$ & $\begin{array}{c}4.94 \\
9.66 \\
13.3 \\
1.93 \\
9.45 \\
0.83 \\
1.8\end{array}$ & $\begin{array}{l}1.8 \\
0.65 \\
1.42 \\
1.30 \\
0.24 \\
0.69 \\
0.66\end{array}$ & $\begin{array}{l}1.45 \\
1.11 \\
1.23 \\
1.77 \\
0.96 \\
1.90 \\
1.33\end{array}$ & $\begin{array}{l}2.63 \\
1.62 \\
2.04 \\
2.32 \\
0.61 \\
0.74 \\
0.80\end{array}$ & $\begin{array}{l}2.13 \\
1.58 \\
1.84 \\
2.76 \\
1.47 \\
2.56 \\
2.11\end{array}$ \\
\hline
\end{tabular}

* Salt-poor diet for three days preceding experiment.
1.39 for sodium and 2.06 for chloride. Pitressin evidently may reduce the response to Mersalyl, and when it does so it raises the peak $U / P$ ratios for sodium and chloride.

\section{DISCUSSION}

\section{The site of action of Mersalyl}

Figures 1, 2, and 3 show that the effect of Mersalyl is to alter the urinary concentration of sodium in such a way that the $U / P$ ratio tends towards unity, irrespective of whether it was initially higher or lower. Chloride behaves similarly, except that the $U / P$ ratio tends towards 1.5 .

In this connection the results obtained by Walker, Bott, Oliver, and MacDowell (12) in their micro-puncture experiments on mammalian kidneys seem to be of great interest. These workers obtained samples of fluid from the renal tubules of guinea-pigs and rats, and analyzed them for chloride, osmotic pressure and (in two instances only) sodium. The site of puncture was identified subsequently by dissection of the tubule. Owing to technical difficulties they were unable to obtain fluid from the lower part of the proximal tubule, and the observations on distal tubules are represented by only three osmotic pressure determinations. They were able, however, to obtain samples from upper proximal tubules on 49 occasions. They found that the osmotic pressure of the fluid so obtained was always close to that of the plasma, and in two instances in which the sodium concentration was determined, this also was found to be very close to that of the plasma. The chloride concentration of this fluid, however, was always higher than that of the plasma; samples taken from the middle third of the proximal tubule all showed chloride $U / P$ ratios of about 1.4, while samples from the first third showed ratios which were lower, but tended nearer to 1.4, the lower down the tubule the puncture was made. Nothing is known as to the composition of fluid in the distal third of the proximal tubule; in the absence of evidence to the contrary it seems likely that the same ratios, 1 for sodium, 1.4 for chloride, exist there also.

The urine obtained at the peak of mercurial diuresis in our experiments in man apparently tends towards the composition of the proximal tubular fluid obtained by micro-puncture experiments in 
rats and guinea-pigs, at least as regards $U / P$ ratios for sodium and chloride, and it is tempting to suggest that this 'peak' urine may represent proximal tubular fluid which has been little if at all altered in its passage through the distal tubules. This might result either from an inhibition of distal reabsorption of salt and water as suggested by Duggan and Pitts (5) or from diminished salt reabsorption in the proximal tubule causing 'flooding' of the distal tubule by proximal tubular fluid and masking of its reabsorptive capacity, as is apparently the case in osmotic diuresis (13). The question cannot be settled by the data on $U / P$ ratios alone, though we feel that the close approach to the ideal ratios in some of our experiments with relatively small diureses probably favors the former hypothesis. Our results, and those of Capps, Wiggins, Axelrod, and Pitts (11) show that Mersalyl in therapeutic doses does not significantly augment a maximum water diuresis. If we assume that the action of pituitary antidiuretic hormone is on the distal tubule, these results support the idea that the action of Mersalyl is similarly located. The results of administration of Mersalyl during a Pitressin infusion are too variable to allow a definite conclusion to be drawn. Thus the results reported here, while not in themselves conclusive, add to the evidence favoring the view that Mersalyl inhibits reabsorption of sodium, chloride, and water in the distal tubule.

\section{SUMMARY}

1. The injection of Mersalyl into normal human subjects caused the $U / P$ ratio for sodium to approach 1 and that for chloride to approach 1.4 , regardless of whether the initial urine concentrations were high or low.

2. Mersalyl was incapable of producing more than a slight augmentation of a maximum water diuresis.

3. When Mersalyl was given during an infusion of pituitary antidiuretic hormone, the results were variable. In some experiments, the diuresis was suppressed completely; in others a diuresis occurred, and the same changes in $U / P$ ratio were seen as in experiments without antidiuretic hormone.

4. These results are considered to favor the view that Mersalyl inhibits reabsorption of sodium, chloride, and water in the distal tubule.

\section{ACKNOWLEDGMENTS}

Our thanks are due to Mr. F. Diggins and Miss V. Holloway for technical assistance; to Miss M. Furnivall for devising, and Mrs. Rhodes and Miss Luget for preparing, the salt-poor diets; to our subjects, for their co-operation, and to Professor G. W. Pickering, for valuable advice and criticism.

\section{REFERENCES}

1. Govaerts, P., L'action diuretique du novasurol estelle d'origine rénale ou tissulaire? Arch. int. Pharmacodyn., 1929, 36, 99.

2. Bartram, E. A., Experimental observations on the effect of various diuretics when injected directly into one renal artery of the dog. J. Clin. Invest., 1932, 11, 1197.

3. Brun, C., Hilden, T., and Raaschou, F., On the effects of Mersalyl on the renal function. Acta pharmacol. et toxicol., 1947, 3, 1.

4. Berliner, R. W., Kennedy, T. J., Jr., and Hilton, J. G., Salyrgan and renal tubular secretion of paraaminohippurate in the dog and man. Am. J. Physiol., 1948, 154, 537.

5. Duggan, J. J., and Pitts, R. F., Studies on diuretics. 1. The site of action of mercurial diuretics. $J$. Clin. Invest., 1950, 29, 365.

6. Mudge, G. H., Foulks, J., and Gilman, A., Effect of urea diuresis on renal excretion of electrolytes. Am. J. Physiol., 1949, 158, 218.

7. Weston, R. E., Grossman, J., and Leiter, L., The effect of mercurial diuretics on renal ammonia and titratable acidity production in acidotic human subjects with reference to site of diuretic action. J. Clin. Invest., 1951, 30, 1262.

8. Sanderson, P. H., Potentiometric determination of chloride in biological fluids. Biochem. J., 1952, 52, 502.

9. Harrison, H. E., A modification of the diphenylamine method for determination of inulin. Proc. Soc. Exper. Biol. \& Med., 1942, 49, 111.

10. Stanbury, S. W., and Thomson, A. E., Diurnal variations in electrolyte excretion. Clin. Sc., 1951, 10, 267.

11. Capps, J. N., Wiggins, W. S., Axelrod, D. R., and Pitts, R. F., The effect of mercurial diuretics on the excretion of water. Circulation, 1952, 6, 82.

12. Walker, A. M., Bott, P. A., Oliver, J., and MacDowell, M. C., The collection and analysis of fluid from single nephrons of the mammalian kidney. Am. J. Physiol., 1941, 134, 580.

13. Rapoport, S., West, C. D., and Brodsky, W. A., Excretion of solutes and osmotic work during osmotic diuresis of hydropenic man. The ideal and the proximal and distal tubular work; the biological maximum of work. Am. J. Physiol., 1949, 157, 363. 